assistant or nurse. The female blade is then passed upward and anterior to the first. To avoid embarrassment in passing the second blade, the patient's hips should well overhang the edge of the bed; otherwise there cannot be free play for the handles. When in position the two handles may be brought together, using caution not to pinch the soft parts, then to be securely locked, and nothing now remains but to apply the extractive force.

The lithotomy position, or that on the back, derived from the custom the French and Germans, is much in vogue at present. I do not condemn it, but the side position has always done well with me, and I like it. By unlocking the forceps at the point when the head distends the perinæum and is about to emerge, and withdrawing the blades singly and gently, perineal rupture may be avoided. But if, unfortunately, rupture should occur, a few sutures or the application of two or three serres-fines and binding the woman's knees together will soon repair the damage.

( To be concluded.)

\title{
PUERPERAL CONVULSIONS. ${ }^{1}$
}

BY hoWland holmes, M. D.

Searching for the cause of eclampsia gravidarum et parturientium, in 1841 Professor Simpson, of Edinburgh, and others pointed at albuminuria, and when, in 1843 , Dr. Lever said Eureka, his co-workers hailed the discovery for a time with admiration and faith, which have gradually grown less to the present time. Dr. Lever thought the convulsions the result of uræmic poisoning, the evidence of which was the albuminous condition of the urine, which he invariably found in this disorder. He furthermore held that pressure of the foetus impaired the free or normal action of the kidneys, causing albuminuria, and he adhered to this view to the last.

The theory of Dr. Lever, substantially, has probably been the predominant one entertained and acted upon ever since. Just previous to and simultaneously with this were the theories of anæmia and hyperæmia of arterial cerebral congestion held by some, and venous cerebral congestion by others, with many recorded and traditionary vagaries. A vast amount of labor and ingenuity has been expended in setting forth these causes and claskifying them into predisposing and exciting causes, but it is sufficient for our purpose to say that pregnancy, with all the altered conditions of the system incident to it, is the chief predisposing cause. And here, strangely enough, I would remark in passing, the best writers are unsettled to-day whether the convulsions are caused by the albuminuria, or the albuminuria is caused by the convulsions. Here,

1 Read before the Middlesex South District Medical Society, April 16, 1879. 
then, is a field for our labor. Let us each and all help settle the question which is cause and which is effect. To explain, directly after the convulsion there is acute, desquamative nephritis: did the convulsion produce this state of the kidney, or was this state of the kidney anterior to the convulsion, and the cause of it? Prominent gynæcologists may be found to support each side of the question.

The convulsions, as I shall have occasion to state farther on, are epileptiform in character, and it is therefore claimed by some that acute nephritis, albuminuria, etc., must be a necessary sequence of an ordinary epileptic fit in either sex. This, gentlemen, affords us another opportunity to assist in settling this point by carefully examining the urine of our epileptic patients both before and after the fit. A frequent and careful examination of both the urine and the blood in the later months of pregnancy and directly after parturition would do much in aid of answering the question whether there is more than a normal amount of urea circulating in the blood, or whether there is albuminuria in all cases of convulsions and prior to them.

It was a well-recognized fact that in chronic forms of Bright's disease uræmia existed, and the frequent occurrence of convulsions in that disease were due to toxæmia, resulting from the retention of urea in the blood. While Frerichs, Braun, and others substantially supported this view, the former modified it so far that he held that the true toxic element was not urea as such, but carbonate of ammonia, resulting from its decomposition. Here, again, has been expended much patient investigation and learned research to settle this question.

About 1861 Dr. Hammond, of Maryland, and other eminent men, after much experimentation, would not concede that urea ever was changed to carbonate of ammonia in the blood. In 1870 Spiegelberg, after experiments on human and canine subjects, supported the theory of Frerichs, while Barnes and others believe that eclampsia may be due not to urea, nor the products of its decomposition, but to other poisonous irritants or excrementitious matters not cognizable to the chemist. Playfair, whose beautiful system of midwifery is familiar to most of you, says it is highly probable that in some cases convulsions and albuminuria are produced by the same cause, and appear simultaneously.

While it is generally conceded that puerperal convulsions are preceded by albuminuria, and that the two are always combined, some assert that eclampsia now and then occurs, though very rarely, without albuminuria, or rather previous to it ; tirst the convulsion, then albuminuria. Braxton Hicks is one of the chief supporters of this view, and is quoted by Playfair. Hicks reported four cases about a dozen years ago, which were published in the eighth volume of Obstetrical Transactions in London; but on examination I find he had seen only two of them personally and in consultation, while the other two were reported to 
him ; and if they were observed as poorly as they are reported, they are not entitled to much reliance. But the two seen by Hicks are far from being conclusive in my mind. Cazeaux had heard of but six cases, all of which, he says, can be satisfactorily set aside. This, then, is a question to be kept distinctly in mind, and answered by our future observation and experience: whether convulsions ever precede albuminaria in any fairly and accurately observed case. My personal belief is that none such exist. The views of Hicks led him to say, "The nearly simultaneous appearance of albuminuria and convulsions must then be explained in one of three ways: First, that the convulsions are the cause of the nephritis. Secondly, that the convulsions and the nephritis are produced by the same cause ; for example, some detrimental ingredient circulating in the blood, irritating both the cerebro-spinal system and other organs at the same time. Thirdly, that the highly congested state of the venous system, induced by the spasm of the glottis in eclampsia, is able to produce the kidney complication."

As none of the theories thus far advanced would satisfactorily explain all the cases that presented, Traube and Rosenstein have assigned acute cerebral anæmia as the cause of eclampsia. In parturient women the blood is ordinarily hydræmic, and when there is albumen the watery condition of the blood is greatly intensified. Accompanying this condition of the blood and the patient, hypertrophy of the heart is said to be normal, and as a result of these combined states is a temporary hyperæmia, which is rapidly succeeded by serous effusion into the cerebral tissues, resulting in pressure on its minute vessels and consequent anæmia. Kussmaul and Tenner have shown more recently the dependence of convulsions on cerebral anæmia, and Brown-Séquard that an anæmic condition of the nerve centres precedes an epileptic attack.

Nearly all of these fine theories call in to their aid the energetic pains of labor as a factor in the causation of convulsions, and, theoretically, they would explain very satisfactorily how the occurrence of labor should intensify the convulsions, since during the acme of the pains the tension of the cerebral arterial system is necessarily greatly increased. But, unfortunately, the convulsions nearly as often occur some hours after the labor is ended. I have not taken pains to procure statistics to show the relative frequency of ante-partum and post-partum convulsions, but the latter are not rare. Moreover, these theories utterly fail to account for the cases which are preceded by well-marked precursory symptoms, and in which an abundance of albumen is present in the urine. Here the premonitory signs are precisely those which precede the development of uræmia in chronic Bright's disease.

If you have thus far been able to follow me while I have so hurriedly and imperfectly passed in review many of the theories of the ætiology and pathology of the disease entertained by the best practitioners and 
writers during the last forty years, I would like to say here that in order to have our future observations and investigations of any value, we must all stand on the same platform and have the disease now under consideration so sharply defined as to be in the focus of observation, and exclude all others. In other words, some writers have hitherto unquestionably included cases of hysteria, epilepsy, and even apoplexy in their list of puerperal convulsions. Playfair says, "In most obstetric works it has been customary to describe three distinct classes of convulsions : the epileptic, the hysterical, and the apoplectic." But a parturient woman, either before or after delivery, may suffer from hysterical paroxysms, or she may be attacked with apoplexy accompanied with coma and followed by paralysis or deatl. But these conditions are identical with the same diseases in females not bearing children, and are in no way special in their nature. In true eclampsia the paroxysms are always epileptiform, and are essentially the same in appearance as those of an ordinary epileptic fit, but their clinical history is different. It is true that the premonitory symptoms of an attack are rarely heeded either by physician or attendants, and consequently the whole house is suddenly startled by the unexpected paroxysm. Nevertheless, there are precursory indications which should be kept constantly in mind by the obstetrician, the most common of which are severe headache, transient attacks of giddiness, confusion of thought, impairment of sight, disjointed remarks, and these symptoms, especially when coupled with œdema of the face or upper extremities, are always ominous. Convulsions with these symptoms, attended also with albuminous urine, may unhesitatingly be pronounced puerperal.

The attack is sudden. The eyes turn obliquely up under the lids, and the head slowly rotates in the same direction; the countenance is terribly distorted, and assumes a horrible expression; the mouth froths, which is soon tinged with blood, unless the tongue be promptly protected. The face soon becomes livid and frightfully altered; the veins of the head and neck are full, hard, and enlarged ; and the patient struggles, shudders, and quivers till the paroxysm subsides. This state of things is sufficient to call into requisition all the physician's resources, even when he is not distracted by the incessant inquiries and exclamations of friends; but the whole household is wild with excitement, and all ask questions and want categorical answers; there is no opportunity to deliberate. As any of us are liable to be called to such a case before we sleep, it is well to carefully consider and determine our course of procedure in advance. To assist us in this, allow me to give the minutes of the last case that came under my notice:-

July 25, 1876, at four o'clock, P. M., I was called in haste to Mrs. W., thirty-two years of age, who, with but thirty minutes' sickness, had surprised herself and friends by giving birth to a child, a girl, weighing 
six pounds. With gentle traction at the cord I removed the placenta, and soon had the mother and child very comfortable. Mrs. W. had borne two children previously, and had been attended in both instances by a physician in a neighboring town, where she then lived, whom she had engaged to be with her in this confinement, but she was surprised, and had no time tn send for him. She confessed to having had some slight twinges of pain for eight hours before the child was born, but did not think she was in labor, and ate and exercised with the rest of the family. Although her delivery was sudden and without an attendant, there was no laceration of the perinæum, and the patient laughed more than once during this interview at the surprise her sudden accouchement had given herself and all her friends, and I left her between four and five P. M. in the best of spirits and perfectly comfortable. That night between twelve and one o'clock, July 26th, I was called to see her in a fit. When I arrived the convulsion had ceased; she was conscious, but her head felt unpleasantly, and so did her chest from her stomach to her pharynx. She had suffedred thus for an hour or more previous to the fit, but from the description by herself and attendants I supposed the fit might be hysterical, treated it as such, and returned to my rest. But I had hardly reached my bed when she had another fit, and I was called again. This convulsion had also subsided, and her consciousness had returned when I reached her the second time. I still thought her trouble might be hysterical, and gave her a liberal dose of morphia, and myself the lounge to await the result.

Her first fit was at 12.30 A. M., her second at two o'clock, A. M., and at $3.40 \mathrm{~A}$. M. she had the third fit, which was the first $I \mathrm{saw}$, and which satisfied me $I$ had something to contend with more than hysteria. From this time she neither swallowed nor was conscious, but lay constantly in a comatose condition. Her former physician, Dr. Willis, of Waltham, saw her in consultation, and at $4.50 \mathrm{~A}$. M. she had another fit. Dr. Willis administered one fourth grain of morphia hypodermically, took urine by catheter, and found it highly albuminous. She had a fit at 5.30 A. M. and at $6.30 \mathrm{~A}$. M., after which we decided to keep her under the influence of ether. At this time her pulse varied from 90 to 96 , and was slightly intermittent. I administered the ether myself, and from her profoundly comatose state between the convulsions it was not easy to determine when she had inhaled just the right quantity. She did not now move a voluntary muscle between the convulsions, which took place at 8.30 A. M., at 10.45 A. M., at 12.30 P. M., and at two o'clock, P. M., when she had her tenth and last fit. Her respiration during these convulsions was of course spasmodic, and more or less stertorous all the time. The severity of the last convulsion, with her cyanotic and exhausted condition, satisfied me she could not survive another such fit. Her friends were telegraphed, and her energies seemed 
to be sinking. The muscles of the neck were rigid, and drew the head backwards; there was opisthotonos, as in well-marked tetanus. During her first convulsions she had bitten her tongue badly, and during the subsequent ones frothy mucus tinged with blond escaped from her mouth, into one side of which $I$ crowded a thickly folded napkin, to guard against any further injury to the tongue.

I ceased to give her ether at a quarter past three o'clock, P. M. At this time she was in a profoundly comatose condition. Her breathing for some time previous had been growing shorter and more thoracic. Her eyes had no expression of life ; her face grew more and more livid or cyanotic ; her feet, hands, and arms, which had been dusky for some hours, seemed to be taking a deeper hue; and the blood under her finger nails was a dark purple.

Dr. Willis saw her again with me about four o'clock, P. M., and after remaining with her an hour we agreed that she was in a moribund condition, and that we could probably be of no further service to her, and we retired. I called three hours later in the evening, fou:d her living, and her hands a trifle less dusky; other appearances the same. Early in the morning, July 27 th, I called again, and learned she had swallowed in the course of the night, and then I satisfied myself that she would sip tea from a spoon and swallow it.

From this time she rallied, and is now perfectly well. Her recovery was very gradual ; her consciousness did not fully return for nearly a week. For several days she lay with her eyes closed, and for two days they appeared to be covered with a film, and looked like the eyes of a person deceased. Her evacuations were passed unconsciously for four days, but each successive day showed an improvement on her previous condition till August 5th, the twelfth day after her confinement, when she suddenly had puerperal mania, imagining all sorts of things, especially that she had taken something which she ought not to, and that she should die that night, etc. She persistently declined to swallow anything for some hours, took her leave of all the family, etc., but in the morning following she was calm and herself again.

Her previous two labors had been of the ordinary type, and she had nursed her two children; but after this confinement there was no secretion of milk whatever. During her convalescence there was nothing peculiar in her treatment; for diet she at first had brandy and milk, afterwards milk without the brandy, then broth, beef tea, etc. She took but little medicine, chiely bromide of potassium, sweet spirits of nitre, with now and then a Dover's powder, and finally the muriated tincture of iron.

Many of you may recall the case reported in the Boston Medical and Surgical Journal, March 13, 1879, by Dr. O. W. Doe, of Boston, in one or two respects not very unlike my own. The convulsions were post 
partum, occurring six hours after delivery instead of nine hours, as in my case. The patient was thirty years of age, the wife of a physician who lived in Boston, and in a few minutes had at her bedside several of the best obstetricians in Massachusetts, if not in New England. She " had a very severe convulsion lasting fully fifteen minutes." Dr. Calvin Ellis, being called, administered ether. Dr. George H. Lyman arrived a few minutes later, and gave half a grain of morphine hypodermically. Dr. Francis Minot, coming soon aftarwards, indorsed the treatment, and advised the continuation of morphia pro re nat $\hat{a}$, and suggested chloral per rectum, which was subsequently given. Still later, enemata, elaterium, croton oil, blood-letting, hot-air bath, and pilocarpine were in turn resorted to, and in less than eleven hours the patient took ether (the quantity not known to the writer, nor the manner of taking it); of morphia hypodermically one half grain, one fourth grain twice, and by the mouth one fifth grain ; of chloral twenty grains per rectum; four enemata - one of soap-suds and sweet oil, one of soap-suds, sweet oil, and turpentine, which was repeated, and one turpentine enema with two drops of croton oil, and one drop upon the tongue; four one-fourthgrain doses of elaterium in butter placed on the tongue; venesection from the right arm resulted in the abstraction of one pint of blood. The hot-air bath was administered by Dr. Bradford. Muriate of pilocarpine one sixth grain was given hypodermically, and repeated.

The treatment in this case is entitled to our very careful consideration. It is the most recent treatment we have for our guidance, and most assuredly it is not what we know as "expectant" treatment. And if some of us regard it as " heroic," very heroic, we must bear in mind the source from which it emanates. This patient made a complete recovery; but had she died, and had we been called upon to give our verdict as to the cause of death, we might have found it embarrassing to decide whether she died of the disease or of the treatment.

But I wish you particularly to note the blood-letting. A few minutes before it the pulse was 108 , respiration 14 , and the report says : " 10.15 A. M., face remained markedly cyanotic. Bled to the extent of a pint from the right arm by Dr. Minot. Pulse 104 directly after the operation. 11.35 A. M., countenance as livid as before the operation." So we see that an hour and twenty minutes after venesection the countenance is not improved, and the pulse only four beats less than before it.

Twenty or thirty years ago there was a publication in England called the Londion Lancet, and in the pocket of every surgeon and physician was a surgical instrument by the same name; and this instrument was used on nearly all occasions, nor has it become entirely obsolete yet. Even Playfair, from whom 1 have several times quoted, approvingly says: "Until quite recently venesection was regarded as the sheetanchor in the treatment, and blood was always removed copiously, and 
there is sufficient reason to believe, with occasional remarkable benefit. .... But while the effects of venesection have been so lauded by certain authors, the mortality has admittedly been lessened since its indiscriminate use has been abandoned."

Dr. Fordyce Barker states that in 1855 the mortality was thirty-two per cent., but has now fallen to fourteen per cent. Against his better judgment the physician is sometimes impelled to practice some bold, decisive, and observable treatment to satisfy the impatient and irrepressible anxiety of relatives. Until the pathology of the disease is more accurately known, can we do better than to protect the patient's tongue by placing a pine stick or folded napkin between the teeth, give ether or chloroform, supplemented by bromide of potassium, chloral, or morphia?

\section{PROCEEDINGS OF THE BOSTON SOCIETY FOR MEDICAL IMPROVEMENT.}

E. G. CUTLER, M. D., BECRETARY.

February, June, and September, 1879 . Uramic Apoplexy. - Reported by Dr. Minot. A gentleman between fifty-five and sixty years of age, single, was brought to the Massachusetts General Hospital, January 28, 1879, in an uncons:ious condition. The history, obtained from the friends, was that he had fallen on the stairs five weeks previously, striking on the temple, and had complained of headuche afterwards, but was able to attend to his business. His habits were perfectly good. On the morning of his entrance he was found in his bed unconsçious, with stertorous breathing, pupils normal, unable to swallow, the head drawn to the left, the right arm and leg paralyzed, and the face flushed. A cicatrix on the right side of the tongue near the tip was noticed, which was not recent. On the 29th it whs observed that there was some movement in the right leg, and occasionally in the right arm, and that the left eye was more open than the right. The head was turned to the left side. Micturition and defæcation were involuntary; the temporal arteries were seen to pulsate strongly; the inspirations were 32 in the minute, and were stertorous. On the morning of the $30 \mathrm{th}$, two hours before death, he was suddenly seized with an epileptic fit, lasting two or three minutes, which was succeeded by another an hour later. The urine was acid, specific giavity 1032, and contained considerable albumen, with hyaline and finely granular casts. The temperature on the evening of his entrance was 100.2。 F.; ou the morning of the $29 \mathrm{th}, 100.8^{\circ} \mathrm{F}$. (taken in the axilla); evening of the $29 \mathrm{th}, 102.6^{\circ} \mathrm{F}$; ; morning of the $30 \mathrm{th}, 100.3^{\circ} \mathrm{F}$; at death, $100.8^{\circ} \mathrm{F}$. (the last three taken in the rectum).

Autopsy. January 31st. Brain. There was a thickening and cedematous condition of the pia mater over the convexities, and a small cyst of the size of a grape seed in the right ventricular nucleus. The kidneys were both diminished to about one half the normal size; the capsules were readily detached, leaving a wrinkled and depressed surface from loss of substance. On section 